\title{
Uso de um vídeo educacional 3D para uma nova óptica das aplicações da energia Nuclear
}

\author{
Marcio Henrique Silva (IEN/CNEN) \\ Ana Paula Legey (NUCAP/UniCarioca/IEN/CNEN) \\ Antônio Carlos A. Mól (NUCAP/UniCarioca/IEN/CNEN \\ Sara Isnardo Fernandes (MPNTDE/UniCarioca) \\ Andre Cotelli do Espirito Santo (NUCAP/UniCarioca/IEN/CNEN) \\ Eugênio Marins (IEN/CNEN)
}

\section{Resumo}

A Energia nuclear abrange várias aplicações úteis à sociedade, como na geração de energia elétrica e diagnósticos médicos. Entretanto, a forma como ela é divulgada muitas vezes contribui para ressaltar apenas o seu lado negativo, fazendo com que a população em geral assuma uma postura temerária em relação ao seu uso. Por essa razão, este trabalho propõe o desenvolvimento de uma abordagem alternativa para divulgar conceitos associados ao tema baseada em um vídeo educacional com recursos 3D sobre as aplicações da energia nuclear, particularmente para alunos de ensino médio em visita ao Instituto de Engenharia Nuclear (IEN/CNEN). Os alunos que participaram desta atividade a classificaram como tendo sido lúdica e prazerosa ressaltando também que o uso do 3D foi capaz de destacar detalhes importantes do conteúdo abordado como: a conversão de energia nuclear em energia elétrica, a distribuição de usinas nucleares no mundo, além de terem contato com aplicações da energia nuclear na área médica. O objetivo deste trabalho é confirmar que a atividade proposta é útil e viável como ferramenta de divulgação científica para fornecer uma informação mais completa, não tendenciosa e que seja capaz de preparar os alunos para argumentações de forma mais crítica e reflexiva.

Palavras-Chave: Aplicações da Energia Nuclear, Divulgação Científica, Vídeos Educativos, Realidade Virtual.

\begin{abstract}
Nuclear energy suits many applications to the society, such as power generation and nuclear medicine, among others. However, nuclear energy has been understood by population in a negative way. Thus, this work's objective is to promote nuclear energy's applications, in particular to high school students who are visitors to the Instituto de Engenharia Nuclear (IEN/CNEN), using 3D movies. They found the activity fun, enjoyable, and the use of $3 D$ video disseminate important details of the contents, such as: (i) power generation; (ii) how it is distributed in some Brazilian cities; (iii) the way nuclear power plants are distributed to cities; (iii) their distribution in the world including Brazil; (IV) the understanding of nuclear energy as a clean; $(v)$ in addition to applications in medicine. It is hoped that the scientific dissemination tool designed encourage people to like the proposed topic and prepare them to be able to reflect and criticize contents on Nuclear Energy.
\end{abstract}

Keywords: Nuclear energy applications, Scientific dissemination, Educational videos, Virtual reality.

\section{Introdução}

A energia nuclear é base de várias aplicações de grande importância para a sociedade atualmente. A cada dia, novas técnicas referentes ao uso desta fonte energética são desenvolvidas nos diversos campos da atividade humana. O exemplo mais conhecido pelo público talvez seja a geração de energia elétrica em usinas nucleares (Rosa, 2007). No entanto, há várias outras aplicações, como na área médica, na indústria e na agricultura, que são pouco conhecidas pela população em geral (Almeida, 2013).

A medicina nuclear é um ótimo exemplo dos benefícios do uso a energia nuclear. Suas técnicas são usadas tanto para o diagnóstico como para o tratamento de diversas doenças, como exemplo o câncer (Cardoso et al., 2009; Xavier et al., 2007). Técnicas nucleares encontram aplicação também em diversos processos industriais 
como a inspeção e ensaios não destrutivos de diversos tipos de materiais, permitindo a identificação de falhas estruturais em peças de aviões, entre outras, que poderiam resultar em acidentes caso não fossem detectadas. Outro exemplo de aplicação é a avaliação da eficiência de misturadores industriais bem como a avaliação de escoamentos multifásicos, com vasta aplicação na área petroquímica, em que é necessário avaliar o fluxo de materiais em mais de um estado (sólido, líquido ou gasoso) em uma tubulação (DUTRA, 2009; Faccini, 2008).

No entanto, estas aplicações ainda permanecem desconhecidas do público geral. Alguns trabalhos apontam que tanto estudantes dos ensino médio e superior quanto o público geral têm noções vagas e desarticuladas sobre radiação e energia nuclear, além de desconhecer seus benefícios como o seu uso na área médica ou suas aplicações industriais (Prestes e Capelleto, 2008; Melo e Garavelli, 2010; Rzyski e Sartori, 2010; Almeida, 2013).

A Energia Nuclear ainda enfrenta grande desconfiança e preconceito pela mesma sociedade que desfruta de suas contribuições. A divulgação através dos diferentes meios de comunicação muitas vezes enfatiza a abordagem dos desastres ambientais, devido ao vazamento de material radioativo a partir de acidentes ocorridos em usinas nucleares (Chernobyl e Fukushima), ou se limita a descrever seu caráter belicista, como no caso das bombas nucleares na segunda Guerra Mundial (Milanez et al., 2006). Segundo Ferreira e Soares (2012) a preocupação quanto à utilização da energia nuclear pela sociedade é muito maior onde a informação é equivocada ou insuficiente.

Diante do exposto, cabe ao Estado e às instituições relacionadas à área nuclear mudar esta visão e evidenciar suas realizações através de uma ampla disseminação de suas atividades, ampliando as formas de comunicação científica. Desta forma, a população em geral poderá conhecer o assunto em questão, refletir e opinar de forma crítica e participar das tomadas de decisão da sociedade referentes ao tema. De acordo com Morton et al. (2009) (apud Ferreira e Soares, 2012) a população estará plenamente empenhada em participar da tomada de decisões, se seus pontos de vista forem levados em consideração e, para tal, devem estar adequadamente informados.

Com base neste cenário, este trabalho se propõe a buscar respostas para duas questões básicas: Como tratar desse tema - energia nuclear e suas aplicações - com uma população repleta de preconceitos? Como divulgar seus conceitos de forma motivadora, mantendo o público atento ao conteúdo proposto, uma vez que os meios de comunicação científica existentes não têm contribuído de forma efetiva para mudar o quadro em questão?

Pensando em uma forma de divulgação científica alternativa que possa ser mais ampla e motivadora é que se buscou nesta pesquisa uma forma de divulgar as aplicações da energia nuclear que atendesse às necessidades recorrentes do público, com uma visão diferenciada, a partir de uma metodologia que proporcione a assimilação do conhecimento por parte dos alunos, para torná-los críticos, reflexivos, interessados e capazes de assumir um posicionamento fundamentado acerca do tema em questão.

A tecnologia tem um importante papel na comunicação de informações, visto que seu uso tem se adequado a atividades ligadas à educação (Teixeira e Brandão, 2003), sejam elas atividades ligadas ao ensino formal ou não formal. $\mathrm{O}$ ato de ensinar e aprender consiste, sobretudo, em uma relação de comunicação e, nesse sentido, a tecnologia se mostra uma grande aliada. Dentro deste contexto, o uso de novas tecnologias visuais pode ser utilizado para proporcionar ambientes mais lúdicos para o ensino de novas informações.

As novas tecnologias são consideradas mediadoras nas atividades didático-pedagógicas como instrumentos de planejamento e realização de projetos interdisciplinares (Timm et al., 2003). A tecnologia tem sido considerada um elemento motivador e desafiador no surgimento de novas práticas, não como uma substituta de antigas praticas de ensino e divulgação científica, mas aliada às existentes, para tornar o processo ensino -aprendizagem uma atividade inovadora, dinâmica, participativa e interativa.

As tecnologias educacionais devem ser usadas em contextos que facilitem a articulação dos saberes importantes nos processos de transformação do conhecimento e experiências da sociedade (Santa-Rosa e Struchiner, 2010) e no preenchimento de lacunas do conhecimento científico de forma duradoura. Além disso, espera-se 
que estas ferramentas sejam usadas como mediadoras neste processo de construção e divulgação do conhecimento científico. Struchiner, Gianella \& Ricciardi (2005) apontam que as novas ferramentas de comunicação têm gerado novas formas de relacionamento social e de ensino.

Uma das tecnologias que têm sido utilizadas é o vídeo educativo, que permite o uso de imagens, animações e narrações associadas ao conteúdo abordado, com objetivo de facilitar a transmissão dessa informação e promover uma melhor assimilação do conteúdo por parte dos espectadores (LEGEY, 2013 a, BRENDIN et al., 2007; PESSÔA, 2012).

Em particular, o uso de vídeos 3D estereoscópicos, elaborados por meio de técnicas de Realidade Virtual (RV), tem se mostrado uma importante ferramenta de motivação do público-alvo (LEGEY, 2013 a, LEGEY, 2013b) no aprendizado de novos conteúdos. Aliada a sua função educativa, foi observada a possibilidade do uso da RV na área de divulgação científica, a fim de divulgar os avanços científicos quanto ao uso da energia nuclear.

De acordo com De Meis (2002), o cientista moderno tem o papel, na sociedade, de ser decodificador e, em sua especialidade, tornar acessível ao público os avanços na sua área específica de trabalho. Uma instituição de pesquisa será tanto mais eficaz em sua função social, quanto mais cientistas/decodificadores dispuser em seus quadros.

Assim sendo, pesquisadores das áreas de engenharia nuclear e divulgação científica do Laboratório de Realidade Virtual (LabRV), do Instituto de Engenharia Nuclear (IEN/CNEN), desenvolveram um vídeo 3D estereoscópico para apresentar um novo ponto de vista sobre a energia nuclear evidenciando os benefícios de seu uso em detrimento da abordagem excessivamente negativista observada atualmente a respeito deste tema.

O objetivo é propor uma nova abordagem da divulgação de conceitos da energia nuclear baseada em novas tecnologias como o vídeo 3D para tornar a atividade mais agradável, lúdica e que possibilite uma melhor compreensão do tema por parte dos alunos do ensino médio, uma vez que este grupo representa uma parcela da sociedade

ainda em formação, que poderá, diante de uma informação completa e livre dos preconceitos gerados pelo medo e pela ignorância observados atualmente com relação a questões envolvendo o assunto, opinar de forma crítica e consciente para que futuramente possam participar da tomada de decisões desta mesma sociedade acerca desta importante questão.

\section{Desenvolvimento do vídeo educativo}

Para definir que temas seriam abordados pelo vídeo, foi realizado um levantamento bibliográfico acerca de algumas aplicações da energia nuclear. Essa bibliografia serviu como base para os roteiros, que foram elaborados em duas colunas, dispostas da seguinte forma: a $1^{\text {a }}$ coluna foi composta por uma imagem criada pela equipe técnica; a $2^{\mathrm{a}}$ coluna foi composta por textos elaborados para a narração. Em seguida, houve a modelagem das imagens para compor o vídeo em 3D. Durante a concepção do vídeo, foi observada a necessidade da elaboração de um material de divulgação de curta duração, com imagens 3D associadas a animações, para atrair a atenção dos alunos para os conceitos abordados, facilitando a assimilação do conhecimento referente aos benefícios da energia nuclear para sociedade, já que a forma negativa já vem sendo comunicada no cotidiano da população.

\section{Desenvolvimento do vídeo}

O LabRV (Mól, 2005) possui uma infraestrutura para o desenvolvimento de trabalhos envolvendo realidade virtual, o que inclui computadores com alto desempenho para aplicações gráficas e televisores 3D. 
A modelagem foi implementada com o uso do software 3Ds Max. Neste trabalho, foi usado o plug-in XidMary a fim de obter cenas em estéreo. A estereoscopia proporciona, a cada olho do espectador, uma imagem correspondente (Hale and Stanney, 2002; Siscouto et al., 2004). A Figura 1 mostra a tela de interface do 3Ds Max evidenciando a modelagem de uma das imagens do vídeo, especificamente um tomógrafo focando o uso da energia nuclear na área médica.

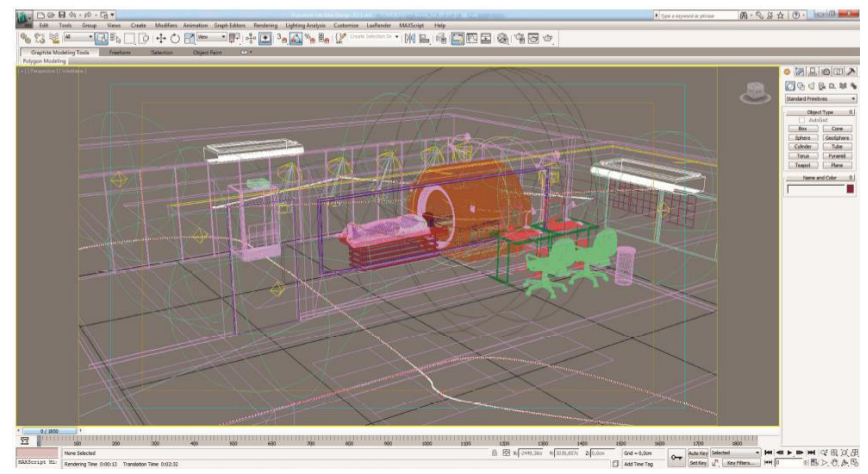

Figura 1 - Interface do 3Ds Max.

A Figura 2 exemplifica a interface do programa Sony Vegas Pro 10.0, com cenas do filme produzido, como o funcionamento de um reator nuclear, utilizado para incluir faixas de áudio usadas: de voz (narrativa) e de música de fundo.

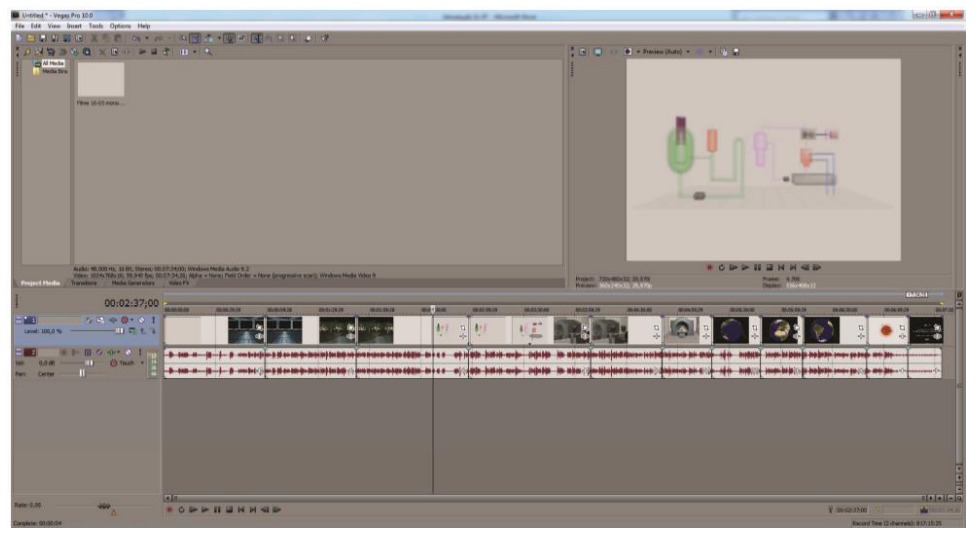

Figura 2 - Interface do programa Sony Vegas Pro 10.0.

O software Adobe After Effects foi usado para gerar arquivos no formato “avi”. Este programa compõe vídeos a partir de quadros gerados pelo 3Ds Max e foi utilizado também para produzir efeitos como modificar a exposição de cores, adicionar novos elementos visuais, manipular áudio, distorcer imagens, remover granulação, melhorar iluminação ou criar transições. Um recurso importante deste software é o uso de keyframes, em que é possível estabelecer o tipo de movimento da animação (rotação, escalamento, entre outros), a velocidade, e informações da animação imediatamente anterior e imediatamente posterior ao quadro em questão. 


\section{Conteúdo abordado}

O conteúdo a ser abordado no vídeo foi definido visando informar aos alunos o que há de mais básico e importante sobre a energia nuclear, desde a definição do que é, de que forma pode ser obtida, até exemplos de algumas de suas aplicações conhecidas atualmente.

Assim sendo, três pontos principais foram destacados: a definição do que é a energia nuclear, explicando qual a sua origem e principais diferenças em relação a outras formas de energia conhecidas atualmente; o uso da energia nuclear na produção de energia elétrica, muito importante no momento atual, em que há no Brasil carência de recursos hídricos e um exemplo de aplicação da energia nuclear na área médica. Incluiu-se, também, um tópico acerca de como estão distribuídas as centrais nucleares pelo mundo.

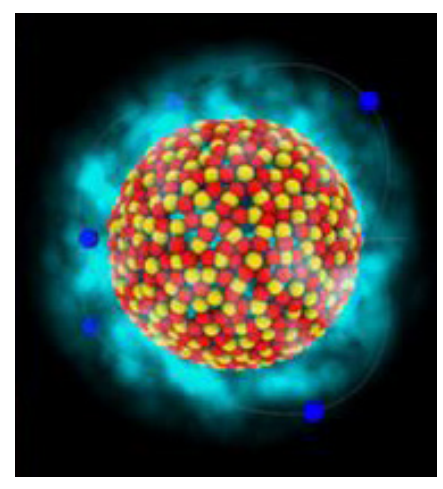

Figura 3 - Núcleo atômico modelado no vídeo.

A Figura 3 apresenta um modelo do núcleo de um átomo, em que se destacam elétrons em azul, prótons em vermelho e nêutrons em amarelo. No vídeo, essa imagem é duplicada para o efeito estereoscópico, e mostra esse átomo e suas partículas em movimento, bem como a energia (a energia de ligação) que mantém prótons e nêutrons confinados no núcleo atômico, mantendo-o coeso. Essa energia, ao ser liberada pela fissão de um átomo, é conhecida como energia nuclear. Durante a reprodução do vídeo ao qual está associada esta imagem, há a explicação acerca do que vem a ser fissão nuclear, evidenciando a divisão do núcleo do átomo original em dois outros átomos menores, com a liberação de nêutrons, como ocorre com o átomo de urânio-235, quando atingido por um nêutron acelerado numa reação que libera calor para o meio externo.

\section{Geração de energia elétrica a partir da energia nuclear}

A figura 4 descreve o modelo de uma usina nuclear. Este exemplo representa o Complexo Nuclear de Angra, como pode ser observado pelas três cidades alimentadas por ela: São Paulo, Belo Horizonte e Rio de Janeiro. A localização estratégica da usina, próxima ao mar, permite o aproveitamento da água no circuito terciário para refrigeração da água do circuito secundário da usina, por meio de bombas rotativas em sistemas fechados, o que dificulta vazamentos. Além disso, os reatores apresentam contenção de aço e concreto, evitando vazamentos tanto para o interior quanto exterior o que evidencia a segurança com que a Usina de Angra opera para geração de energia elétrica. 


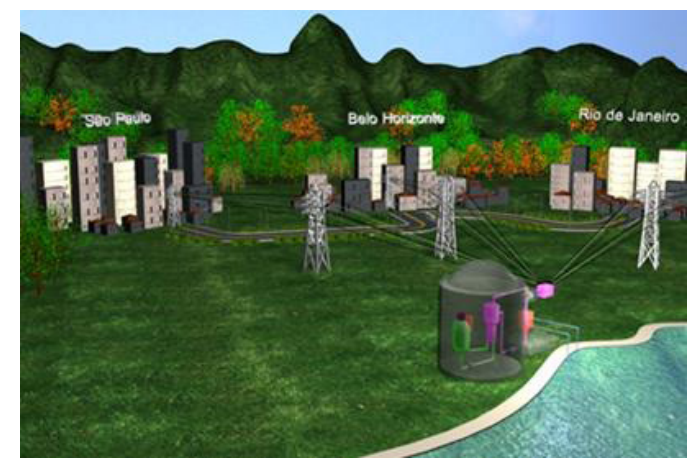

Figura 4 - Modelo do complexo nuclear de Angra 1

\section{O reator PWR}

A Figura 5 ilustra um reator nuclear do tipo PWR (do inglês Pressurized Water Rector, ou reator a água pressurizada) com seus respectivos circuitos. Nele ocorrem reações de fissão nuclear controladas para obtenção de energia elétrica. Durante a exibição do vídeo, esta imagem fica bem próxima ao espectador. O modelo do reator gira 3600, mostrando seu funcionamento, ou seja, a geração de energia elétrica a partir do combustível nuclear, o isótopo 235 do Urânio. É destacado que, por se tratar de um processo controlado, não há risco de ocorrer explosões durante as fissões nucleares em cadeia. É um sistema seguro, pois a concentração de urânio é baixa e as reações não são rápidas o suficiente para que sejam geradas explosões, além de reaproveitamento dos nêutrons para controlar as fissões nucleares em cadeia.

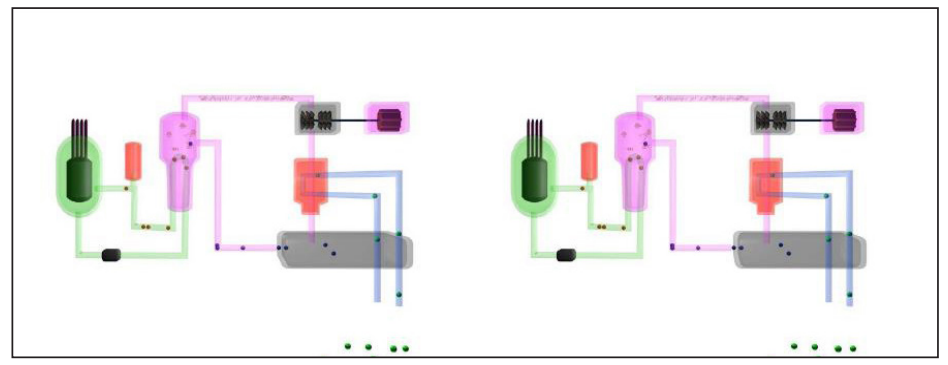

Figura 5: Modelo de um reator nuclear PWR com seus respectivos circuitos

Durante o funcionamento virtual do reator, é mostrado o circuito primário (em verde) com a água de refrigeração que fica circulando no núcleo do reator. Este circuito fica em movimento e em evidência ao espectador. Em seguida, é colocado em evidência na tela e bem próximo ao espectador o circuito secundário (em rosa), que consiste na geração de vapor de água para acionar a turbina do reator. Por último, é mostrado o circuito terciário (em laranja). Esses sistemas são independentes e com uma barreira de aço que impede vazamentos de radiação para o exterior. 


\section{Distribuição das centrais nucleares no mundo}

A Figura 6 ilustra o momento do vídeo em que é apresentada a distribuição de usinas nucleares ao redor do Mundo (pontos em laranja), mostrando países que possuem a geração nuclear como grande parte de sua matriz energética e outros, como o Brasil, em que a energia nuclear ainda é um pequeno potencial de sua matriz.

Neste quadro, o efeito 3D tem maior destaque, pois mostra o globo terrestre girando, bem próximo ao espectador, para salientar todos os países que apresentam usinas nucleares.

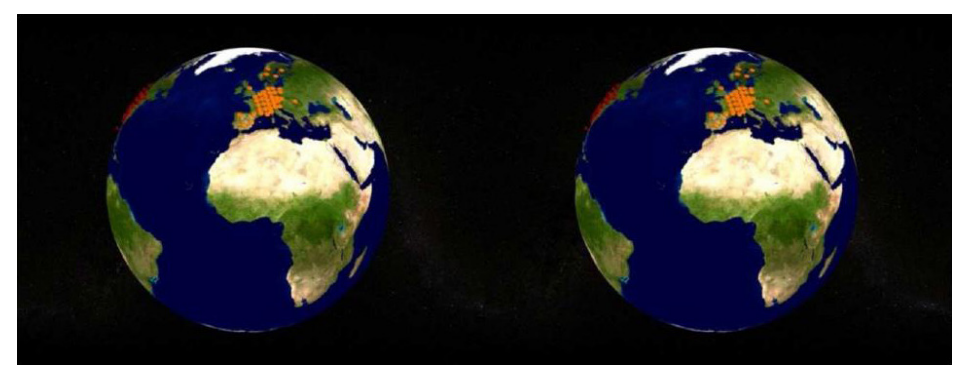

Figura 6: Distribuição das usinas nucleares no mundo

\section{Aplicação da energia nuclear na medicina}

A Figura 7 ilustra uma cena do vídeo que narra uma das aplicações da energia nuclear na medicina. A área de diagnóstico tem sido uma das áreas mais promissoras na medicina, mas que ainda é ignorada pela maioria da população. A imagem do vídeo descreve um tomógrafo em $3 \mathrm{D}$, que permite um diagnóstico rápido e eficiente para que haja tratamento precoce e seguro de doenças como câncer de tireoide.

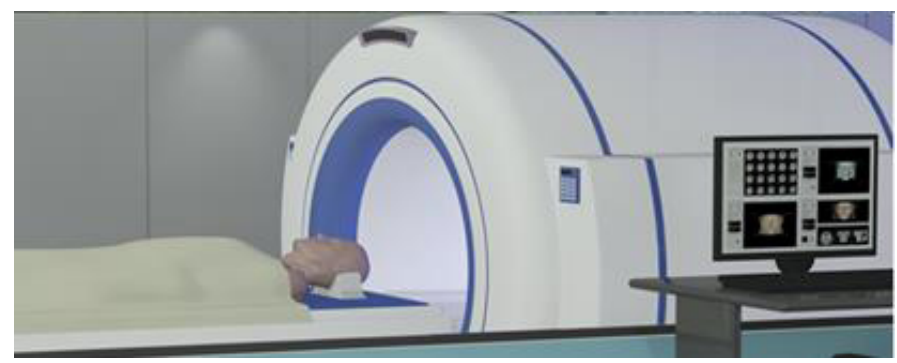

Figura 7: Tomógrafo 3D.

Existe uma mesa para o paciente deitar-se, que desliza para o interior do tomógrafo. No aparelho, identificase um suporte circular (Gantry), que tem em uma das extremidades um tubo que emite radiação ionizante, e, em outra, detectores de radiação que enviam imagens para um computador.

\section{Apresentação do vídeo}

A instalação do LabRV (Mól, 2005) inclui uma sala de projeção, com um tela de 3 x 2m, e dois projetores. Este ambiente pode ser usado para avaliações, durante o desenvolvimento de atividades, ou para aplicação final com o público desejado. Nesta pesquisa, um total de 57 alunos de ensino médio de escolas públicas, sendo 
1 grupo de 17 alunos, 1 grupo de 14 alunos e 2 grupos de 13 alunos, visitaram o LabRV em dias diferentes, acompanhados por seus professores. Antes da exibição do vídeo, os alunos assistiram a uma palestra acerca das atividades desenvolvidas no LabRV e das aplicações da Energia Nuclear.

\section{Instrumento de coleta de dados}

Foi elaborado um questionário com objetivo de avaliar (i) se o vídeo em 3D foi uma estratégia que propiciou uma forma motivadora de divulgar as aplicações da energia nuclear; (ii) o que os alunos acharam de mais interessante na atividade proposta e (iii) se o conteúdo apresentado foi assimilado de forma efetiva pelos alunos. Para tal finalidade, os questionário foram aplicados após a exibição do vídeo educativo no LabRV do IEN. Antes da aplicação, os alunos responderam a um termo de consentimento livre esclarecido (TCLE), que os convidou a participar como voluntários da pesquisa para o esclarecimento, principalmente, dos objetivos e dos benefícios da pesquisa proposta. Para a análise dos dados obtidos, foi utilizada a técnica de análise de conteúdo, como proposta por Bardin (1977).

De acordo com Bardin (1977), o conceito definido como análise de conteúdo é caracterizado como sendo "um conjunto de técnicas de análise das comunicações visando obter, por procedimentos sistemáticos e objetivos de descrição do conteúdo das mensagens, indicadores (sejam eles quantitativos ou não) que permitam a inferência de conhecimentos relativos às condições de produção/ recepção desta mensagem" (Bardin, 1977, p.47).

A técnica consiste em três fases básicas: a pré-análise, a exploração do material e, finalmente, o tratamento dos resultados em que ocorrem a inferência e interpretação. Uma descrição competente e de fácil compreensão, não só destas três fases como da técnica em si, pode ser encontrada em (Câmara, 2013), onde também são apresentados exemplos práticos.

\section{Análise dos resultados}

O vídeo foi apresentado aos estudantes do ensino médio em uma sala de exibição do LABRV do Instituto de Engenharia Nuclear (IEN/CNEN). Foi observado que todos os alunos participaram da atividade proposta com entusiasmo e atenção. Após a exibição do vídeo, os alunos responderam às questões de avaliação da atividade proposta. Vale ressaltar que todos os participantes da pesquisa responderam ao questionário proposto.

O questionário compunha-se de questões abertas e, para extração e avaliação dos dados, foram identificadas categorias de análise levantadas a partir das respostas dos alunos. Foram utilizadas duas questões norteadoras a partir das quais transcorreu toda a análise referente ao objetivo deste estudo. São elas:

Questão norteadora 1:

Como você avalia a atividade em relação aos recursos que ela disponibiliza para tratar do tema abordado?

Questão norteadora 2:

Com relação ao conteúdo abordado, qual(ais) informação(ões) mais chamou(chamaram) sua atenção?

O objetivo de tais questões é obter informações referentes à forma como (ou se) a nova tecnologia incorporada à prática educativa foi capaz de contribuir para a otimização do aprendizado e consequente assimilação do conteúdo apresentado (no caso da questão 01) e, dentro daquilo que se pretendia apresentar, o que foi entendido como sendo mais importante pelo público-alvo da atividade (questão 02). 


\section{Avaliação dos dados obtidos}

A análise de conteúdo feita a partir das respostas dos alunos foi realizada segundo o que indica Bardin (1977). Assim sendo, a primeira fase (pré-análise), onde ocorre a formulação das hipóteses e objetivos, respeitou as regras de exaustividade, homogeneidade, pertinência e exclusividade. A estrutura de trabalho adotada nesta pesquisa é semelhante àquela utilizada em Câmara (2013). Por essa razão, a preparação do material coletado se fez editando as respostas dos alunos às questões norteadoras, onde os temas comuns foram organizados. Após a transcrição dos dados ocorre a leitura flutuante para que seja feita a categorização do conteúdo de acordo com o que sugere Bardin (1977).

De forma sucinta, a segunda fase (exploração do material) compreende codificação, classificação e categorização. Como afirma Câmara (2013), "a classificação em blocos expressa categorias que confirmam ou modificam aquelas que estavam presentes nas hipóteses e referenciais teóricos inicialmente propostos”.

Assim, num movimento contínuo da teoria para os dados e vice-versa, as categorias vão se tornando cada vez mais claras e apropriadas ao propósito do estudo. (Câmara, 2013).

Os quadros 1 e 2 (nos anexos 1 e 2, respectivamente) mostram como é feita a organização do material. Por fim, ocorre a terceira fase do processo de análise de conteúdo (tratamento de resultados), na qual são feitas inferências e interpretações. "Calcado nos resultados brutos, o pesquisador procurará torná-los significativos e válidos. Esta interpretação deverá ir além do conteúdo manifesto dos documentos, pois interessa ao pesquisador o conteúdo latente, o sentido que se encontra por trás do imediatamente aprendido" (Câmara, 2013).

Os dados obtidos ao final da análise indicaram que o uso de novas tecnologias, em particular o vídeo estereoscópico 3-D, no ensino de conceitos associados à energia nuclear, é capaz de produzir resultados satisfatórios com relação ao processo ensino-aprendizagem do tema, facilitando seu entendimento e permitindo uma melhor compreensão das informações.

Tendo em vista que o Brasil vive uma crise hídrica sem precedentes, é importante adotar formas alternativas para a produção de energia elétrica. Nesse contexto, a energia nuclear se mostra como uma opção viável, segura e de baixo impacto ambiental. Porém, acidentes como de Fukushima (provocado por processos naturais, não por falha de equipamentos) contribuem para o reforço de uma imagem negativa da energia nuclear pela população.

Os resultados desta pesquisa mostram que, com a correta apresentação do tema “energia nuclear”, é possível entender melhor o assunto, superando vícios e inculcações propagados de forma irresponsável pela mídia já há alguns anos. Os recursos visuais utilizados também contribuíram para manter a atenção dos alunos voltada para a atividade, o que contribuiu para uma assimilação mais eficaz do conteúdo.

\section{Discussão}

Está preconizado, a partir dos Parâmetros Curriculares Nacionais (PCN, 2000) que o aluno do ensino fundamental deve comparar o funcionamento das hidroelétricas com as termoelétricas, como o funcionamento das termonucleares; discutir sobre as transformações das formas de energia, sua origem e os recursos tecnológicos necessários às suas transformações, com enfoque nos problemas de impacto ambiental ligados aos diferentes modos de obter energia, tema que pode ser trabalhado com auxílio de interpretação e debate de artigos de jornal e revistas de circulação nacional, enfatizando casos específicos como, por exemplo, o vazamento de material radiativo e os riscos que representam ao ambiente e à saúde do ser humano.

Desta forma, o aluno ao ingressar no ensino médio apresenta o conhecimento sedimentado apenas com uma das visões da energia nuclear: os riscos. Terrazzan (1992) e Lobato (2005) afirmam que as aplicações da energia nuclear são pouco exploradas ou, ainda, que as informações sobre o tema dão ênfase apenas aos aci- 
dentes nucleares. Nesse sentido, os educadores deveriam explorar também os benefícios da energia nuclear à sociedade. Esta é a proposta deste trabalho.

Recursos como vídeos educativos podem ser dispositivos motivadores do ensino, assim como são ferramentas utilizadas para sensibilizar o expectador e torná-lo mais receptivo aos conteúdos abordados (Rezende e Struchiner, 2009). Consideramos o vídeo desenvolvido neste trabalho não apenas como uma ferramenta de divulgação dos benefícios da energia nuclear no contexto do ensino não formal, mas também como uma ferramenta de disseminação do conhecimento.

Ainda segundo as diretrizes dos Parâmetros Curriculares Nacionais, além do livro didático, outras fontes oferecem informação ao cidadão: museus, centros de pesquisa, folhetos educativos, jornais, revistas de divulgação científica e vídeos educativos (PCN,2000). Neste sentido, novas tecnologias de informação e comunicação, como o uso de vídeos, em especial o vídeo em 3D, constituem recursos auxiliares no aprendizado.

O indivíduo pode obter conhecimento através da visualização de modelos baseados na realidade, favorecendo a assimilação ou reformulação de conceitos de maneira mais eficiente do que a aula tradicional com quadro-negro e giz (Gonçalves, 2006), o que pode ser corroborado com os resultados apresentados: os alunos afirmaram que o vídeo 3D proporcionou maior interatividade, além de terem a sensação de realidade, como ocorreu na cena, por exemplo, do funcionamento do reator nuclear, citada como a que mais chamou atenção aos alunos.

Atividades lúdicas podem promover um melhor desenvolvimento cognitivo, tornando os alunos mais aptos, além de proporcionar uma experiência reflexiva (Ferreira, 2003). Além disso, informações gravadas com mais intensidade são lembradas mais facilmente. $\mathrm{E}$ as emoções agradáveis poderão contribuir de forma mais eficaz para fixar a realidade do que uma aula tradicional, longa (De Meis, 2002).

Existem alguns conteúdos da área de ciências que devem ser ensinados com intuito de favorecer a análise crítica de temas atuais de nossa sociedade. Desta maneira, materiais educativos têm o papel de estimular alunos na construção do conhecimento além de fazê-los indagar e refletir sobre o conteúdo científico proposto, sendo assim mais reflexivos e críticos (Auler e Delizoicov, 2006; Rosa e Rosa, 2005; Ramos e Neves, 2004; Vannucchi, 2004; Auler, 2003).

A atividade proposta utiliza uma tecnologia diferenciada e motivadora que permite divulgar os conceitos da área nuclear de uma forma mais eficiente e ensiná-los de modo a atrair a atenção do público-alvo a detalhes que permitem um novo ponto de vista acerca do tema apresentado, evidenciando o conteúdo científico sob um ângulo positivo, pouco vislumbrado no ensino formal (Prestes et al., 2008; Melo; Garaveli, 2010), e não explorados pela mídia (Meldonian e Mattos, 1997) como, por exemplo: o que é a energia nuclear, como ocorre o funcionamento de um reator para geração de energia, como ocorre a distribuição de energia elétrica nas cidades, quais as possíveis aplicações da energia nuclear na área médica.

Quando indagados quanto ao que acharam de mais interessante no vídeo, os alunos observaram que, além de ser uma estratégia diferenciada para aprender um novo conteúdo cientifico, foi um recurso que permitiu o conhecimento das aplicações da energia nuclear, enfatizando o conhecimento da geração de energia elétrica a partir da energia nuclear, o funcionamento de um reator nuclear e as aplicações na área médica, como, por exemplo, o uso em tomógrafos.

Da mesma forma, ao serem questionados quanto ao conteúdo assimilado em razão do vídeo, os estudantes elaboraram respostas que contemplaram os objetivos propostos, destacando-se que compreenderam como a energia elétrica é gerada a partir da energia nuclear, como funciona um reator nuclear, como se dá a distribuição das usinas no mundo e no Brasil, como a energia nuclear pode ser aplicada na área de saúde; os estudantes identificaram também que é uma energia limpa e não poluente. As repostas evidenciaram que prestaram atenção à mensagem proposta pelo vídeo e reconheceram os benefícios da energia nuclear à sociedade. 
A maioria dos alunos citou que a energia nuclear é não poluente e sua utilização em larga escala colaboraria com desenvolvimento sustentável no nosso país. A indústria nuclear como um todo, incluindo a produção de energia elétrica e toda a indústria do ciclo do combustível nuclear, seria uma alternativa existente para a produção de energia elétrica em grandes quantidades. A produção de energia elétrica por meio da energia nuclear tem sido considerada importante na proteção do meio ambiente, uma vez que a energia nuclear não emite poluentes que afetariam a camada de ozônio, como o dióxido de carbono, ou material teratogênico ou mutagênico, entre eles Arsênio, Mercúrio, Chumbo, Cádmio, como ocorre no caso das usinas que utilizam combustível fóssil (Cerconi, Melquiades e Torminaga, 2009).

O grau de desenvolvimento científico e tecnológico dos países pode estar diretamente associado à melhoria da qualidade de vida; sendo assim, a divulgação científica pode aproximar a sociedade dos benefícios a que ela tem o direito. Os divulgadores científicos devem garantir que os significados dos conhecimentos científicos sejam aprendidos pela população e que sejam correspondentes àqueles que os cientistas validam (De Meis, 2002). Porém, os avanços científicos, nas últimas décadas, têm sido divulgados de maneira acelerada e, muitas vezes, de forma equivocada e sensacionalista (Jurberg, 2000).

Para permitir que a comunidade se aproprie do conhecimento obtido, os currículos devem não apenas ser atualizados; é necessário também que haja uma abordagem mais integrada dos problemas da sociedade, nos quais os conhecimentos científicos (como, por exemplo, os relacionados à energia nuclear) estão envolvidos.

Um dos maiores desafios do século XXI é levar à sociedade o conhecimento científico, discutindo seus riscos e benefícios e promovendo um diálogo razoável entre cientistas e o restante da sociedade (Jurberg, 2000; Maia e Gomes, 2006). É importante que a população compreenda as mudanças do mundo contemporâneo, como a influência da ciência e tecnologia nas estratégias industriais e na expectativa de vida da população. É preciso que a sociedade esteja preparada para debater sobre os avanços científicos que ocorrem em todas as nações do mundo.

Duarte (2004) discute a cultura da comunicação, que tem como objetivo aproximar a sociedade das questões de ciência, ao permitir sensações como ver, sentir e tocar, ao despertar vocações, ao estimular o debate, ao tornar ciência parte de cada vida, ao fazer com que o cidadão tenha uma relação lúdica com a ciência, incorporando-a a seu universo e tornando-se crítico, participante e capaz de refletir sobre ela. Para tal, além das escolas, a comunidade científica deve contribuir para tornar o ensino transformador e criativo em todos os níveis, socialmente construído, validado, além de propiciar o bom desempenho do aprendizado de forma estimulante (Zancan, 2000).

As escolas não são os únicos locais onde os indivíduos aprendem conceitos científicos ou percebem a natureza da ciência como uma atividade intelectual. Museus de ciências assim como instituições de pesquisa apresentam a potencialidade de ampliação e melhoria do conhecimento científico de estudantes, bem como da população em geral (Lucas, 1991; Uko, 1985). Estes locais podem proporcionar à sociedade a (in)formação técnico-científica e humanística necessária à leitura do mundo.

A educação não formal pode ser definida como a que proporciona a aprendizagem de conteúdos da escolarização formal em espaços como a mídia, museus, centros de ciências, ou qualquer outro em que as atividades sejam desenvolvidas de forma bem direcionada, com um objetivo definido (Gohm, 1999).

Os espaços de educação não formal despontam como parceiros de uma ação pedagógica, transmitindo valores e padrões de conduta, socializando muitas gerações. Além disso, Domingos e Recena (2010) defendem espaços para desenvolvê-los e utilizá-los. Nesse sentido, os pesquisadores do Instituto de Engenharia Nuclear propiciaram, além do material didático, vídeo em 3D, um espaço diferencial para divulgação e reflexão quanto às aplicações da energia nuclear. 


\section{Conclusão}

Este trabalho propõem o uso de um vídeo estereoscópico com recursos 3-D como uma tentativa de oferecer uma concepção diferenciada para o ensino não formal da energia nuclear e suas aplicações para alunos do ensino médio em visita ao Instituto de Engenharia Nuclear (IEN/CNEN). Esta estratégia inovadora contribuiu para a expansão dos processos de aprendizagem, o que permitiu um maior envolvimento dos alunos, além de ser considerada uma forma estimulante de apreender novos conteúdos. Finalmente, foi alcançado o objetivo proposto, que é apresentar o conceito de uma forma não tendenciosa para propiciar um novo olhar acerca da energia nuclear e dos benefícios que podem trazer para a sociedade. Espera-se que a ferramenta de divulgação científica criada possa incentivá-los a gostar do tema proposto e prepará-los para futuras argumentações de forma crítica e reflexiva.

\section{Agradecimentos}

Agradecemos à Fundação de Amparo à Pesquisa do Estado do Rio de Janeiro (FAPERJ) e ao Conselho Nacional de Desenvolvimento Científico e tecnológico (CNPq), que financiou esta pesquisa. Agradecemos também à Comissão Nacional de Energia Nuclear (CNEN), em particular ao Instituto de Engenharia Nuclear (IEN/CNEN), por fornecer os recursos para o desenvolvimento deste trabalho. Financiamento: FAPERJ: E/26/111.832/2013, CNPq: bolsas de iniciação científica.

\section{Referências bibliográficas}

Auler, D. (2003). Alfabetização Científico Tecnológica: Um novo "paradigma"? Ensaio - Pesquisa em Educação em Ciências, 5, 1, 1-16. Em: http://www.portal.fae.ufmg.br/seer/index.php/ensaio/article/viewFile/60/97.

Auler, D.; Delizoicov, D. (2006). Educação CTS: Articulação entre pressupostos do educador Paulo Freire e referenciais ligados ao movimento CTS. In: Lópes, A.B.; Peinado, V.B.; Lópes, M.J.; Ruz, M.T.P. (Orgs.). Las Relaciones CTS en la Educación Científica (pp. 1-7). Málaga: Editora da Universidade de Málaga.

Almeida, R.A. (2013). Um estudo simplificado sobre a percepção pública na área nuclear: sugestões para campanhas educativas para os diferentes segmentos da sociedade. M.Sc. Dissertation, Instituto de Engenharia Nuclear, CNEN, Rio de Janeiro, RJ, Brazil.

Bardin, L. (1977). Análise de conteúdo. Lisboa: Edições 70.

Brendim, M.; Rezende, L.; Silva, A., (2007). Entre a informação e a motivação: uma análise de vídeos educativos para prevenção e detecção precoce do câncer de cabeça e pescoço. VI ENPEC, Anais.

Câmara, R. H., (2013). Análise de conteúdo: da teoria à prática em pesquisas sociais aplicadas às organizações. Revista Interinstitucional de Psicologia, 6, 2, 179-191.

Cardoso, E.M.; Alves, P.A.; Braz, C.; Pestana S. (2009). Apostila Educativa: Aplicações da Energia Nuclear. CNEN, Rio de Janeiro. Em:http://www.sjt.com.br/tecnico/gestao/arquivosportal/file/ENERGIA\%20NUCLEAR\%20-\%20APLICA\%C3\%87\%C3\%95ES\%20 -\%20CNEN.pdf.

Cerconi, C.; Melquiades, F.L. and Tominaga, T.T. (2009). Energia Nuclear, o que é necessário saber. RECEN - Revista Ciências Exatas e Naturais, 11, 1, 9-34.

De Meis, L. (2002). Ciência, educação e o conflito humano e tecnológico. São Paulo: Editora Senac SP.

Domingos, D.C.A., Recena, M.C.P. (2010). Elaboração de jogos didáticos no processo de ensino e aprendizagem de química: a construção do conhecimento. Ciências \& Cognição, 15, 1, 272-281.

Duarte, N. (2004). Formação do indivíduo, consciência e alienação: o ser humano na psicologia de A. N. Leontiev. Cadernos Cedes, $24,62,44-63$.

Dutra, M., A., M., (2009), "Avaliação Acustoelástica do aço 20 MnMoNi 55, Material Estrutural do Vaso de Pressão dos Reatores Nucleares de Angra II E III", M.Sc. Dissertation, Universidade Federal do Rio de Janeiro, Rio de Janeiro, RJ, Brasil.

Faccini, J. L. H., (2008), “Estudo de Escoamentos Bifásicos Estratificados Usando Técnicas Ultra-Sônicas”, D.Sc. Thesys, COPPE - Universidade Federal do Rio de Janeiro, Rio de Janeiro, RJ, Brasil.

Ferreira, M. C., (2003). O papel da prática reflexiva do professor: uma experiência de aprimoramento de jogos com questões de Física. M.Sc. Dissertation Faculdade de Ciência, Universidade Estadual Paulista Júlio de Mesquita Filho, Bauru, São Paulo.

Ferreira, V. V. M., Soares, W. A. (2012). Insucessos em empreendimentos nucleares devido a falhas em processos de Comunicação. INTERCOM-São Paulo,.35, 2, 313-329.

Gohm, M.G. (1999). Educação não-formal e cultura política. Impactos sobre o associativismo do terceiro setor. São Paulo: Cortez.

Gonçalves, L.J., Veit E.A., Silveira F. L., (2006). Textos, animações e vídeos para o ensino-aprendizagem de física Térmica no ensino médio. Experiências em Ensino de Ciências, 1, 1, 33-42. 
Hale, K.S. and Stanney, K.M. (2002). Handbook of Virtual Environments: Design, Implementation and Applications. Mahwah: Lawrence Erlbaum Associates, Inc., Publishers.

Jurberg, C. (2000). Ciência ao alcance de todos: experiências de educação à distância em jornalismo científico. D.Sc. Thesys, Universidade Federal do Rio de Janeiro, Rio de Janeiro, RJ, Brasil.

Legey, A.P., Sá, F.S.G., Maciel, B.B., Bernardo, T.C.M., Chelles, D.R. , Passos, C.A., Mol, A.C.A., (2013a). Desenvolvimento de vídeos estereoscópicos 3D para o ensino na área médica. Revista de Ciência e Tecnologia, 3, 2.

Legey, A.P., Reis, A. B., Passos, C.A., Freitas, V., Rolando, R. F., Mol, A.C.A., (2013b). Framework para desenvolvimento de jogos computacionais educativos. Revista de Ciência e Tecnologia. , 4, 83 - 101.

Lobato, T., Greca, I.M. (2005). Análise da inserção de conteúdos de teoria quântica nos currículos de Física no Ensino Médio. Ciência \& Educação, 11, 1, 119-132.

Lucas, A.M. (1991). Info trainment and informal sauce for learning science. International Journal of Science education, 13, 50, 495-504.

Maia, K.F.B., Gomes, A.C.A. (2006). Para pensar o fazer e a pesquisa em divulgação científica e jornalismo científico. XXIX Congresso Brasileiro de Ciências da Comunicação, Universidade de Brasília, Brasília, Brasil.

Meldonian, N. L. , Mattos,, L. A.T., (1997). Rejeitos radioativos gerados na usina de Angra I e na produção de radioisótopos para finalidades médico - industriais. Em: Joint Nuclear Conference IV ENAN, August 18 - 22, 1997, Poços de Caldas, Brasil. E 05 Section - Waste Management. Proceedings...Poços de Caldas, MG, Brasil.

Melo, M.F.S. and Garavelli, S.L. (2010). Conhecimento e Aceitação da Energia Atômica pelos alunos do Curso de Física da Universidade Católica de Brasília. B.Sc. Dissertation, Universidade Católica de Brasília, Brasília, Brasil.

Milanez, J.V.; Almeida, R.D.; Carmo, F.S. (2006). Energia Nuclear Socialmente aceitável como solução possível para a demanda energética brasileira. Revista Ciências do Ambiente On-Line, 2, 1, 1-10. Em: http://sistemas.ib.unicamp.br/be310/index.php/ be310/article/viewFile/41/27

Mól, A.C.A.; Grecco, C.H.S.; Carvalho, P.V.R.; Oliveira, M.V.; Santos, I.J.A.L.; Augusto, S.C., Viana Filho, A.M. (2005). Implementation of the Immersive Virtual Reality Laboratory in Nuclear Engineering Institute. 2005 International Nuclear Atlantic Conference (INAC 2005), August 28 - September 02, Santos, SP, Brazil.

Morton, A., Airoldi, M., Phillips, L. (2009). Nuclear Risk Management on Stage: a Decision Analysis Perspective on the UK's Committee on Radioactive Waste Management. Risk Analysis, 29, 5, 764-779.

PCN, (2000) - Brasil,Parâmetros Curriculares Nacionais-Ciências Naturais.

Pessôa, L.R.; Salgado, M.B.B., (2012). Educação, saúde e audiovisual: relações possíveis e desejáveis. Revista Tempus Actas de Saúde Coletiva, 6, 2, 79-84.

Prestes, M; Cappelleto, E. and Santos, A.C.K. (2008). Concepções Dos Estudantes Sobre Radiações. XI Encontro de Pesquisa em Ensino de Física, Curitiba, PR, Brasil.

Ramos, F.P., Neves, L.A. (2004). A importância da estruturação do jogo na formação da subjetividade e na construção da cidadania. Psicopedagogia "on line". Em: http://www.psicopedagogia.com.br/artigos/artigo.asp?entrlD=572.

Rezende, L.A., Struchiner, M., (2009). Uma Proposta Pedagógica para Produção e Utilização de Materiais Audiovisuais no Ensino de Ciências: análise de um vídeo sobre entomologia. Revista de Educação em Ciência e Tecnologia, 2, 1, 45-66, mar. 2009.

Rosa, C.V., Rosa, A.B. (2005). Ensino de Física: objetivos e imposições no ensino médio. Revista Electrónica de Enseñanza de las Ciencias, 4, 1. In: http://www.saum.uvigo.es/reec/volumenes/volumen4/ART2_Vol4_N1.pdf.

Rosa, L.P. (2007). Geração hidrelétrica, termelétrica e nuclear. Estudos Avançados, 21, 59, 39-58.

Rzyski, B.M. and Sartori, C. (2010). Avaliação Do Conhecimento Da População Paulistana Sobre A Energia Nuclear E Os Rejeitos Radioativos - O Acidente De Goiânia Despertou O Interesse? Em: http://www.ipen.br/biblioteca/cd/go10anosdep/Cnen/doc/ manu10.PDF

Santa-Rosa \& Struchiner (2010). Design Participativo de um Ambiente Virtual de Aprendizagem de Histologia. Revista Brasileira de Pesquisa em Educação em Ciências, 10, 2.

Siscouto, R.A.; Szemberg, F.; Tori, R.; Raposo, A.B.; Celes, W. and Gattass, M. (2004). Estereoscopia. In: Kirner, C. and Tori, R. (Ed.), Realidade Virtual: Conceitos e tendências (pp. 179-201). São Paulo: Ed. Mania de Livros.

Struchiner, M.; Gianella, T.R.; Ricciardi, R.M.V. (2005). Novas tecnologias de Informação e Educação em Saúde diante da Revolução Comunicacional e Informacional. Em: Minayo, M.C.S. e Coimbra Jr, C.E.A (Org.). Críticas e atuantes: ciências sociais e humanas em saúde na América Latina. Rio de Janeiro: FIOCRUZ, p. 257-272.

Teixeira e Brandão (2003). Software educacional: o difícil começo. Novas Tecnologias da Educação. CINTED-UFRGS, 1, 1, 1-7.

Terrazan, C.A. (1992). A Inserção da Física Moderna e Contemporânea no Ensino de Física na escola de $2^{\circ}$ Grau. Caderno Brasileiro de Ensino de Física, 9, 3, 209-214.

Timm, M.I., Schaid, F., Zaro, M., Ferreira Filho, R.C.M., Cabral, P.A.F., Rosa, A.M., Azevedo, M., Jesus, M.A.S., (2003). Tecnologia educacional: mídias e suas linguagens. Novas Tecnologias da Educação. CINTED-UFRGS 1(1): 1-19

Uko, D.A. (1985). Science literacy and science museus exhibts. Curator: The Museum Journal, 28, 4, 287-300.

Vannucchi, A.I. (2004). A Relação Ciência, Tecnologia e Sociedade no Ensino de Ciências. Em: Carvalho, A.M.P. (Ed.) Ensino de Ciências Unindo a Pesquisa e a Prática (pp. 77). São Paulo: Pioneira Thomson Learning Ltda. 
Xavier, A.M.; Lima, A.G.; Vigna, C.R.M.; Verbi, F.M.; Bortoleto, G.G.; Gorajeb, K.; Collins, C.H.; Bueno, M.I.M.S. (2007). Marcos da História da Radioatividade e Tendências Atuais. Química Nova, 30, 1, 83-91.

Zancan, G.T. (2000). Educação científica: uma prioridade nacional. São Paulo em Perspectiva; 14, 1, 3-7.

Anexo

Categoria: Os recursos computacionais proporcionaram melhor compreensão do tema

Definição: Os recursos computacionais que acompanham o vídeo 3-D proporcionaram uma experiência mais rica e agradável, contribuindo para uma melhor assimilação do tema proposto. De acordo com o que foi exposto pelos alunos, características como a qualidade das imagens apresentadas, agilidade na forma de explicar o tema além da sensação de imersão, favorecem a compreensão do assunto estudado, além de possibilitar um tipo de interação com o conteúdo que não seria possível apenas com a leitura de um livro, por exemplo. A tecnologia 3-D permite descrever os conceitos com a ajuda de recursos gráficos que possuem movimento em $360 \mathrm{o}$ e isto contribui para agilizar o processo ensino-aprendizagem como um todo. Além disso, a qualidade das imagens torna o vídeo mais atraente e permite explorar melhor as informações que são apresentadas, atraindo a atenção dos estudantes de maneira mais eficiente que outros métodos convencionais.

\begin{tabular}{|l|l|}
\hline Temas & Exemplos de Verbalização \\
\hline Efeito 3-D este- \\
reoscópico & $\begin{array}{l}\text { - "Contribuiu para explicar de forma rápida e resu- } \\
\text { mida todo o processo de geração de energia." } \\
\text { nuclear." } \\
\text { - "Ajuda pessoas que não têm muito conhecimento } \\
\text { do uso da energia nuclear a entender." } \\
\text { - "Facilita o aprendizado, pois deixa o aluno mais } \\
\text { atento por ser algo interessante e divertido." } \\
\text { - "Ficamos mais entusiasmados e visualizamos } \\
\text { melhor os exemplos" } \\
\text { - "Sim, pois tendo o vídeo 3D o aluno presta mais } \\
\text { atenção à aula, logo tem um melhor entendimento." } \\
\text { - "Por ser algo que não é muito comum costuma } \\
\text { prender mais a atenção das pessoas." } \\
\text { - "A explicação sobre como ocorre, onde e o que } \\
\text { acontece quando se usa a energia nuclear, e com o } \\
\text { 3D é ainda mais motivante." }\end{array}$ \\
\hline $\begin{array}{l}\text { Qualidade das } \\
\text { imagens }\end{array}$ & $\begin{array}{l}\text { - "A qualidade da imagem e a simplicidade e a clareza } \\
\text { com que as informações foram passadas, auxiliando a } \\
\text { fácil compreensão das informaços." } \\
\text { - "Trabalha bastante com o visual do aluno, deixa } \\
\text { bastante fixado à aula. Isso seria bom, pois os alunos } \\
\text { ficam entretidos, logo menos dispersos." } \\
\text { - "Nos ajuda a entender melhor, além de termos a } \\
\text { sensação de estarmos em contato real." } \\
\text { - "O vídeo mostra de forma simples os processos que } \\
\text { utilizam a energia nuclear." } \\
\text { - "Explica detalhadamente o processo de produção } \\
\text { de energia." }\end{array}$ \\
\hline
\end{tabular}

Quadro 1 : Categoria referente à questão norteadora 1. 


\section{Anexo 2}

Categoria: O conteúdo abordado melhorou a compreensão do tema ajudando a superar preconceitos por parte dos alunos sobre o tema

Definição: O conteúdo abordado contribuiu para um melhor entendimento de algumas questões básicas relacionadas à geração e aplicações da energia nuclear. Os alunos destacaram os pontos abordados no vídeo que consideraram mais significativos. Mencionaram a quantidade de usinas nucleares no Brasil em comparação aos EUA; a transformação da energia nuclear em energia elétrica, confirmando que o conceito foi compreendido adequadamente; o funcionamento de um reator PWR, além de diferenças entre a energia nuclear e outras fontes energéticas com relação ao meio ambiente.

\begin{tabular}{|c|c|}
\hline Temas & Exemplos de Verbalização \\
\hline $\begin{array}{l}\text { Produção de energia } \\
\text { elétrica a partir de } \\
\text { um reator PWR }\end{array}$ & $\begin{array}{l}\text { - "Trabalham com } 3 \text { partes: uma que esquenta, outra vaporiza e gera energia após rodar e fazer } \\
\text { gerador funcionar." } \\
\text { - "Aprendi como ocorrem as transformações desta energia para energia elétrica." } \\
\text { - "Produção de energia elétrica (processo em que a energia nuclear possibilita a transforma- } \\
\text { ção da energia térmica em energia mecânica nas turbinas, produzindo energia elétrica através } \\
\text { dessa conversão.)" } \\
\text { - "Produção de energia elétrica (processo em que a energia nuclear possibilita a transforma- } \\
\text { ção da energia térmica em energia mecânica nas turbinas, produzindo energia elétrica através } \\
\text { dessa conversão.)" } \\
\text { - "Como o elemento urânio é utilizado no processo de geração de energia." }\end{array}$ \\
\hline
\end{tabular}




\begin{tabular}{|l|l|}
\hline Energia limpa & \begin{tabular}{l} 
- "O principal aprendizado para mim foi o fato de saber que a energia nuclear não traz dano \\
ao ambiente." \\
- "É uma energia limpa e polui menos o ambiente." \\
- "Onde a energia pode ser utilizada e que a mesma não é poluente." \\
- "Além de proteger o meio ambiente produz muito mais energia com menos material além de \\
ter aplicações em diferentes áreas". \\
- "Não polui o meio ambiente"; \\
- "Não agride muito o meio ambiente." \\
- "Não faz mal ao meio ambiente e até reduz aos problemas ambientais relacionadas ao clima." \\
\hline $\begin{array}{l}\text { Aplicações na área } \\
\text { médica }\end{array}$
\end{tabular} \mid $\begin{array}{l}\text { - "Uso na área de radiofármacos." } \\
\text { - "Que a energia nuclear possui diversas utilizações para a saúde e na obtenção de energia." } \\
\text { - "Que não serve apenas para gerar energia, mas também o seu uso na medicina." } \\
\text { - "Pode ser usada na tomografia." }\end{array}$ \\
\hline
\end{tabular}

Quadro 2 : Categoria referente à questão norteadora 2. 